Revista Científica de FAREM-Estelí

Medio ambiente. tecnología y desarrollo humano

Año 10 | Edición especial: artículos de revisión documental

ISSN: 2305-5790

https://rcientificaesteli.unan.edu.ni

DOI: https://doi.org/10.5377/farem.v0i0.11611

\section{La competitividad de la micro, pequeña y mediana empresa mediante la gestión de sus recursos}

\section{The competitiveness of the micro, small and medium-sized enterprises through the management of their resources}

\section{Fabio José Gaitán Aguilera}

Maestría en Gerencia Empresarial (UNAN-Managua), estudiante de doctorado en Gestión y Calidad de la Investigación Científica II Cohorte 2020-2023 (UNAN-

Managua). Docente de la Universidad Nacional Autónoma de Nicaragua, FAREMEstelí.

https://orcid.org/0000-0002-6280-1087

fgaitan3@yahoo.com

\section{Natalia Sergueyevna Golovina}

Tutora de tesis doctoral, PhD. en Ciencias Sociales, profesora Titular de UNANManagua, FAREM-Matagalpa.

https://orcid.org/0000-0001-9081-6748

natygolovina@gmail.com

\section{RESUMEN}

El presente artículo resulta de la revisión documental de fundamentos teóricos relacionados con la competitividad de la micro, pequeña y mediana empresa (mipyme) mediante la gestión de sus recursos. Se pretende mostrar postulados teóricos administrativos que permitan analizar la importancia e implementación de los distintos componentes de gestión empresarial, que contribuyan a optimizar sus recursos, mayor competitividad y sostenibilidad en el mercado. La base metodológica consistió en revisión bibliográfica de fuentes relacionadas con competitividad y gestión de los recursos, en libros, revistas científicas y tesis doctorales, consultadas en las bases de datos suscritas de la Universidad Nacional Autónoma de Nicaragua, Managua (UNAN-Managua), el repositorio Centroamericano del Consejo Nacional de Universidades (CNU), Google académico, entre otras. En su desarrollo, se abordan fundamentos de la Administración moderna, importancia de la gestión empresarial para lograr la competitividad, centrándose en la gestión de recursos. La Administración de una empresa se enfoca en actividades tanto internas para el control y optimización de recursos, como externas para elaborar estrategias que permitan aprovechar oportunidades y contrarrestar acciones de la competencia, por tal razón, propietarios y gerentes de las mipymes deben dominar y aplicar estos conocimientos para lograr mayor competitividad que conduzca a la sostenibilidad y crecimiento empresarial.
RECIBIDO

$26 / 03 / 2021$

ACEPTADO

19/052021

\section{PALABRAS CLAVE}

Gestión empresarial; competitividad; sostenibilidad; recursos; mipymes. 


\section{ABSTRACT}

This article is the results of the documentary review of theorical foundations related to the competitiveness of the micro, small, and medium-sized enterprise (MSMEs) though the management of their resources. It is intended to show administrative theorical postulates that allow analyzing the importance and implementation of the different components of the business management, which contribute to optimize their resources, greater competitiveness and sustainability in the market. The methodological basis consisted in the bibliographic review of sources related to competitiveness and resources management, in books, scientific journals and doctoral theses, consultation in the subscribed databases of the National Autonomous University of Nicaragua, Managua (UNAN-Managua), the Central American repository of the National Council of universities (CNU), Google Academic, among others. In its development, it approaches the fundamentals of modern administration, the importance of business management to achieve competitiveness, focusing on resource management. The Administration of a company focuses on internal activities for the control and optimization of resources as well as external activities to develop strategies to take advantages of opportunities and counteract competitive actions. For this reason, owners and managers of the MSMEs should master and apply this knowledge to achieve greater competitiveness that leads to sustainability and business growth.

\section{KEYWORDS}

Business management; competitiveness; sustainability; resources; MSMEs. 


\section{INTRODUCCIÓN}

Actualmente las empresas desarrollan sus operaciones en un ambiente dinámico y cambiante, tanto a nivel mundial como nacional. El entorno competitivo es cada vez más exigente, por lo que deben desarrollar estrategias que le permitan su sostenibilidad en el mercado, para lo cual es necesario una buena gestión empresarial de los diferentes recursos. La situación actual es muy compleja y es necesario tener una visión de futuro, sobre los distintos elementos cambiantes del entorno que pueden influir en la gestión administrativa de un negocio.

El objetivo principal de este estudio documental es determinar postulados teóricos administrativos, que permitan analizar la importancia de los distintos componentes de la gestión empresarial y la adecuada implementación de estos, que contribuyan a la optimización de sus recursos y mayor competitividad y sostenibilidad en el mercado.

La capacidad de gestión de una empresa, sus estrategias empresariales y la gestión de innovación, son elementos que las diferencian entre ellas; es decir, cada una de las destrezas empresariales que demuestre la organización frente a sus competidores, determinará su nivel y permanencia en el mercado. Amorós, Becerra y Díaz (2007) definen la gestión empresarial de la siguiente manera:

Es la actividad empresarial que busca a través de personas (como directores institucionales, gerentes, productores, consultores y expertos) mejorar la productividad y por ende la competitividad de las empresas o negocios. Una óptima gestión no busca sólo hacer las cosas mejor, lo más importante es hacer mejor las cosas correctas y en ese sentido es necesario identificar los factores que influyen en el éxito o mejor resultado de la gestión. (pág. 19)

Toda empresa define metas por alcanzar, para esto se requiere una acción coordinada entre los distintos recursos humanos con que cuenta, lo que incide en una mejor productividad, competitividad y sostenibilidad. Esto se logra analizando el ambiente empresarial para identificar los factores que repercuten ya sea generando oportunidades o representando amenazas, que conlleve a la empresa a definir estrategias competitivas que maximicen los beneficios con los recursos con que cuenta.

Es importante comprender que para llevar a cabo una buena gestión empresarial es necesario que el análisis parta de cada estructura y las condiciones particulares que posee cada organización, al respecto Solís (2018) indica lo siguiente:

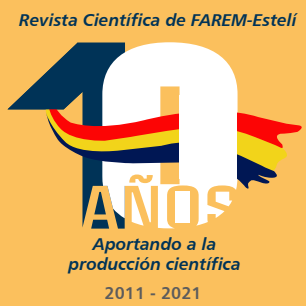


Razonar sobre el uso de la gestión administrativa a partir de las áreas funcionales, pero estas deben ser las que existan en la empresa, pues sus recursos están disponibles para esa estructura en particular y no para estructuras que la literatura clásica nos permite. (pág. 35)

La problemática planteada en esta investigación documental es de mucha importancia, ya que, está inmersa en un contexto real, por el que atraviesan las mipymes en general en Nicaragua, en el cual es fundamental identificar aquellos aspectos que están incidiendo en el fracaso o la baja rentabilidad de los negocios, tales como: estrategias de mercadeo, controles contables y financieros y la aplicación del proceso administrativo.

La limitación en cuanto a este tipo de estudio radica en que no existen muchas investigaciones nacionales o locales, que se puedan retomar como base o punto de partida para profundizar y analizar de manera más integral la situación por la que atraviesan la micro, pequeña y mediana empresa en Nicaragua.

El contenido de este análisis aborda los fundamentos teóricos administrativos, el cual comprende los principales enfoques teóricos que sirven de base a la gestión administrativa, de manera consecutiva se desarrolla la importancia y las áreas de gestión empresarial en las mipymes vista como sistema, realizándose al final las conclusiones sobre esta temática.

\section{MATERIALES Y MÉTODOS}

La metodología empleada para elaborar este artículo científico consistió en una revisión bibliográfica de fuentes relacionadas con las teorías administrativas y gestión empresarial. Para ello se consultaron las bases de datos suscritas de la UNAN -Managua, el repositorio Centroamericano del CNU y Google académico. Las fuentes en las que se indagó fueron libros, artículos de revistas científicas y tesis doctorales.

Los datos encontrados han permitido realizar el estudio y análisis de contenido sobre los postulados teóricos de los precursores de la Administración, así como los elementos relacionados con los distintos tipos de gestión que se realizan dentro de una empresa. Este estudio muestra la importancia de la puesta en práctica de una buena administración que se refleja en una mejor competitividad y sostenibilidad empresarial de las mipymes.

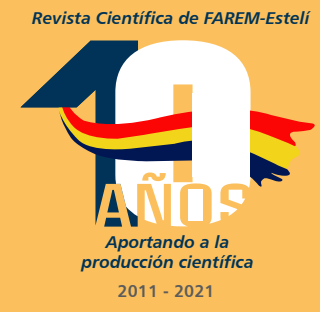




\section{RESULTADOS}

\section{Fundamentos teóricos Administrativos}

Para comprender y aplicar el proceso de gestión administrativa de las mipymes, es necesario conocer las bases teóricas que a través del tiempo y la experiencia han venido desarrollando y sustentando los diversos precursores de la Administración que han conducido a la forma de Administración actual de las empresas. Entre los principales enfoques teóricos que dan base a la gestión administrativa, está la teoría científica de la administración, la teoría clásica, teoría de relaciones humanas, teoría científica del comportamiento, teoría del desarrollo organizacional, teoría de sistemas, teoría burocrática y teoría de contingencia.

La Administración como ciencia moderna logra desarrollarse fundamentalmente a partir de las contribuciones de Frederick Winslow Taylor, en 1911, con lo que se conoce como administración científica. Los aportes de Taylor han sido de mucha importancia en la gestión administrativa al enfocarse en buscar el hombre idóneo para cada función, la preparación y desarrollo científico del obrero, así como una buena relación de trabajo y apoyo entre la dirección y el personal (Jiménez, citado por Araujo (2015)).

En la Administración actual de las empresas lo vemos reflejado en el proceso de reclutamiento y selección de personal, imprescindible para la ubicación adecuada de una persona en un cargo de acuerdo al perfil necesario en un puesto de trabajo.

Chiavenato (2007) hace referencia a la Administración científica de Taylor al indicar lo siguiente:

La Administración científica es una combinación de ciencia en lugar de empirismo; armonía en vez de discordia; cooperación en vez de individualismo; rendimiento máximo en lugar de producción reducida. En fin, desarrollo de cada hombre para alcanzar mayor eficiencia y prosperidad. (pág. 49)

Un aporte esencial de Taylor a la administración es la implementación del método científico buscando a reemplazar la práctica de ensayo y error que se venían haciendo desde la antigüedad, mediante este, aspiraba racionalizar el comportamiento de los trabajadores, enfocándose primero en mejorar las labores realizadas por los colaboradores o empleados operativos para luego llevarlo a los otros niveles de la organización, como resultado se dio la sistematización de las operaciones y determinar la mejor manera de realizar una tarea incrementando la eficiencia y de esta manera la productividad (Araujo Lobo, 2015). La aplicación de este método, vino a reemplazar las actividades arbitrarias y caprichosas de los directivos por procedimientos analíticos y científicos. 
En 1916 surgió en Francia la Teoría clásica de la administración creada por Henri Fayol, si la Administración científica se caracterizaba por hacer énfasis en la tarea que realiza el operario racionalizando su trabajo, la Teoría clásica se distinguía por el énfasis en la estructura que debe tener una organización para lograr la eficiencia, el propósito en común de ambas teorías es buscar la eficiencia en las organizaciones (Chiavenato, 2007).

Al analizar el trabajo de Fayol, sus principios y teorías permiten hoy que los administradores cuenten con normas que les facilite resolver dificultades en el campo de dirección y en la eficiencia y productividad de los recursos humanos; al proponer la división de funciones condujo a la departamentalización y por ende la especialización en el trabajo.

Uno de los elementos esenciales para lograr una buena posición en el ambiente empresarial, está determinado por la efectividad del componente humano que posee, lograr este propósito requiere contar una buena estructura que este en correspondencia con la estrategia de la empresa sustentada por personas con las habilidades y la especialización requerida, la cual se logra a través de una efectiva división del trabajo.

Koontz, Weihrich, Cannice (2012), al respecto mencionan lo siguiente: "Henry Fayol es conocido como el padre de la teoría de la administración moderna. Dividió las actividades industriales en seis grupos: técnico, comercial, financiero, de seguridad, contable y gerencial" (págs. 16-17).

La Administración actual se ha venido enriqueciendo de estudios y experiencias en este campo, que con los cambios económico sociales que se han dado a nivel mundial ha generado elementos que han mejorado la efectividad enfocados en el bienestar tanto del lado patronal como el de los colaboradores. Taylor y Fayol se preocuparon en cómo mejorar la eficiencia del trabajador y de la dirección, pero descuidaron el elemento humano que es determinante en la productividad, surgiendo de esta manera el enfoque de las relaciones humanas preocupado en la importancia que representan los colaboradores en una organización.

La teoría de las relaciones humanas destaca la relevancia de las personas de la organización en el logro de los objetivos, enfocándose en la motivación de los individuos como seres psicológicos y en la influencia de las actitudes y relaciones sociales de los grupos de trabajo en el desempeño (Reyes Ponce, 2007). El efecto inmediato de un buen sistema de motivación a los colaboradores se refleja en el incremento de la productividad.

Lograr la motivación de los colaboradores es tarea de los líderes de una organización, no solo se requiere de incentivos monetarios sino también de propiciar un buen clima organizacional que se manifieste mediante relaciones cordiales tanto entre compañeros de trabajo como entre éstos y sus jefes. En la medida en que la organización cuente con colaboradores motivados sus resultados se inclinarán a una mejor posición competitiva. 
Basándose en la teoría de relaciones humanas surge la teoría del comportamiento, la que se inició con Herbert Alexander Simón, haciendo énfasis en que el administrador necesita conocer las necesidades para comprender mejor la conducta humana y utilizar la motivación como un medio poderoso para mejorar la calidad de vida dentro de las organizaciones (Chiavenato, 2007), esto requiere por lo tanto del estudio de la conducta individual de las personas.

Es de mucho valor destacar el aporte de esta teoría para el logro de los objetivos empresariales. El liderazgo, estudio de la motivación humana, la buena comunicación, el clima organizacional, los incentivos, condiciones de trabajo adecuadas, entre otros, son características organizacionales que le dan un enfoque humanista a la Administración.

Derivada de la teoría del comportamiento, se origina la Teoría del Desarrollo Organizacional (DO). Sánchez (2009) indica que: "El DO busca perpetuarse en el pensamiento administrativo al presentar desde sus orí-genes, un concepto dinámico de las organizaciones, de la cultura organizacional y el cambio organizacional".

Porras y Robertson (citado por Guizar (2013)) lo define:

El desarrollo organizacional es una serie de teorías, valores, estrategias y técnicas basadas en las ciencias de la conducta y orientadas al cambio planificado del escenario de trabajo de una organización, con el propósito de incrementar el desarrollo individual y de mejorar el desempeño de la organización, mediante la alteración de las conductas de los miembros de la organización en el trabajo. (pág. 6)

Al analizar la posición de esta teoría, es de singular importancia el aporte que brinda al campo administrativo, ya que ha venido a dar las pautas para considerar el desarrollo y crecimiento simultaneo tanto de los colaboradores como de los sistemas y procesos en una organización. En las empresas no se deben desarrollar nuevas tecnologías y procesos sin tomar en cuenta que aunado a esto debe ir el desarrollo del personal, esto genera desmotivación y cuellos de botella en algunos procesos lo que vuelve más lento al sistema en su conjunto.

En cuanto a la Teoría de Sistemas, este vino a darle un enfoque global, una unidad de propósitos a la organización, aun cuando las organizaciones están formadas por distintos departamentos se persigue un mismo objetivo organizacional. Esta contribución en el campo administrativo es de mucha relevancia ya que estipula que, aunque se tengan objetivos por departamentos - unidades la visión debe estar puesta en el objetivo general por lo que se debe estudiar a los sistemas globalmente, involucrando a todas las interdependencias de sus partes (Chiavenato, 2007). Cada unidad o área de la estructura organizativa de una empresa debe integrar sus objetivos con las otras para el logro de las metas de la empresa. 
Tener una visión de sistema requiere que los departamentos de la organización no adopten rivalidad y competencia entre ellos, lo cual ocasiona algunas veces efectos negativos en los resultados. Para ser competitivo es necesario que las organizaciones actúen como un sistema, con una sola visión e intereses en común que, aun teniendo funciones y recursos diferentes, estos deben orientarse al logro de los objetivos organizacionales.

Barnard (como se citó en Koontz et al., (2012)) realizó aportes a la administración en cuanto a funciones gerenciales "La tarea de los gerentes es mantener un sistema de esfuerzo cooperativo en una organización formal. Sugirió un enfoque de sistemas sociales amplio a administrar" (pág. 17).

El entorno cambiante requiere de la adaptación de las empresas tanto en su estrategia como en su estructura organizativa. La competencia en la actualidad requiere que las organizaciones tengan colaboradores que dominen su campo de trabajo de modo que puedan tomar las mejores decisiones.

Bajo la premisa anterior, la contribución de la Teoría Burocrática Administrativa, la cual surgió en 1940 desarrollada por Max Weber, se fundamenta en la forma de organización jerárquica del trabajo donde los funcionarios o trabajadores están especializados en su campo y funciones mediante el diseño de una estructura organizacional denominada burocracia (Ramirez Cardona, 2010). El contar con un organigrama permite definir la autoridad y responsabilidad de cada cargo, así como la optimización de los recursos humanos.

Al respecto, fundamentando el propósito de la teoría burocrática, Hernández (201 1), indica que "En este sentido la administración burocrática se configura en la forma racional de ejercer la dominación con precisión, continuidad, disciplina, rigor y confianza, y se orienta al cumplimiento de fines emanados del ejercicio propio de la dominación" (pág. 45).

La teoría de contingencia señala, que las acciones administrativas apropiadas en una situación determinada, dependen de los parámetros particulares de la situación. Las exigencias establecidas por las condiciones contextuales determinan el comportamiento de los miembros de la organización (Zapata Rotundo, 2014),esto indica que las decisiones a tomar van a depender del ambiente particular de cada empresa condicionada por el entorno en que se desenvuelve.

En el mundo globalizado actual en que las mipymes compiten, los entornos son diferentes determinados por políticas gubernamentales, tratados comerciales, condiciones económicas, sociales, culturales y tecnológicas que proporcionan diferentes escenarios competitivos y por lo tanto requieren acciones particulares acordes al contexto en que se encuentren. 


\section{Importancia de la Gestión Empresarial}

Las teorías administrativas antes expuestas, conducen por una serie de bases conceptuales que guían el pensamiento administrativo, pero cuando existen diversas teorías todas bien fundamentadas es importante definir una doctrina que permita la generación de nuevas ideas para aplicar en nuevas realidades del entorno en que se desenvuelven las empresas.

Por esta razón, es importante establecer la diferencia entre las teorías administrativas y la gestión. La perspectiva de la teoría administrativa sienta las bases teóricas del proceso administrativo que se aplica en una empresa y la gestión se encarga de llevar a cabo objetivos organizacionales previamente establecidos (Solís Cedeño, 2018), los cuales se deben alcanzar a partir de la estructura y recursos existente ya que cada una difiere.

Las organizaciones son sistemas abiertos que se adaptan a los cambios del entorno. La Gestión empresarial implica concebir a la organización como un todo interconectado, que mediante la formulación de estrategias flexibles permitan la adaptación más que dar respuesta a un plan formalizado (López \& Mariño Arevalo, 2010). Es preciso que los gerentes diseñen sistemas de información que permitan la toma de decisiones oportunas.

El ambiente en que se mueven actualmente las empresas es muy dinámico, no tiene que pasar mucho tiempo para que las empresas adapten o modifiquen sus productos o servicios, esto requiere una vigilancia constante de su entorno competitivo que conduzca a la empresa a modificar sus estrategias en correspondencia con los cambios demográficos, sociales, culturales, tecnológicos o de cualquier otra índole que se requiera para mantener su posición en el mercado.

El proceso de gestión consiste en la ejecución de las distintas actividades de las áreas de una organización basadas en los principios, normas y políticas administrativas definidas por la organización, sustentadas en las teorías administrativas básicas existentes. Es importante indicar que, sin importar el tamaño, aun siendo una microempresa es necesario la aplicación del proceso administrativo en el tipo de gestión de recursos pertinente a su quehacer, esto se convierte en algo imperativo debido a las limitaciones de recursos con los que cuentan las mipymes y a la necesidad de racionalización de estos para ser más eficientes, eficaces y lograr con lo que posee una buena aceptación en el mercado.

\section{Áreas de gestión empresarial en las mipymes}

Desde el enfoque del estudio de la administración de las mipymes, según Solís (2018), Mora (2008), Saavedra, Tapia y Aguilar (2016), hacen referencia a las actividades con mayor grado de ejecución funcional por parte de los administradores y gerentes en los distintos tipos de empresas, siendo 
estas: gestión administrativa, gestión financiera contable, gestión del talento humano, gestión de abastecimiento, gestión del conocimiento e innovación y gestión de comercialización.

\section{Gestión administrativa}

Independientemente del área de gestión o nivel administrativo, en cualquier empresa están inmersos los pilares del proceso administrativo que comprenden acciones para poder alcanzar los objetivos organizacionales, Mendoza (como se citó en Galarza, Mora, Zambrano (2020)) refiere que: "La gestión administrativa tiene un carácter sistémico, al ser portadora de acciones coherentemente orientadas al logro de los objetivos a través del cumplimiento de las funciones clásicas de la gestión en el proceso administrativo: planear, organizar, dirigir y controlar". (pág. 3)

La gestión administrativa comprende la interacción de los distintos elementos del proceso administrativo, mediante la aplicación correcta de los componentes de este proceso se puede dar seguimiento a los distintos proyectos $\circ$ actividades permitiendo la racionalización delos recursos humanos, financieros y materiales. (Inciarte, Marcano, \& Reyes, 2006).

Las fases administrativas en mención, están inmersas en cada una de las actividades y en todos los niveles de la organización; la puesta en práctica de estos define un proceso que conlleva a la racionalización de sus recursos, lo cual hace a la empresa más competitiva al disminuir sus costos operativos y ofrecer mejores precios en sus bienes o servicios ofrecidos.

La gestión administrativa se relaciona con el manejo cotidiano de los recursos, enmarcada en el diseño de una estructura que asigna funciones y responsabilidades para ejercer un buen control. Rivas (2011) refiere que la aplicación del control interno busca la eficiencia, reducción de riesgo, protección de recursos y confiabilidad de la información basándose en el cumplimiento de los reglamentos. Cuando una empresa logra la eficiencia operativa se encuentra en una mejor posición para competir en el mercado.

Dentro del proceso de gestión de los recursos de una empresa es de mucha importancia disponer de un buen sistema de control, este permite que lo ejecutado se realice conforme a lo planificado evitando así la desviación de recursos hacia otras actividades o excederse en el uso de los mismos. Para la eficiente aplicación del proceso de control se requiere que exista una estructura y responsabilidades definidas que permita medir los resultados ya sea por área o persona asignada a un cargo.

Como elemento primordial para el éxito en las micro y pequeñas empresas está el compromiso de los colaboradores, que son los responsables de la ejecución de los planes en conjunto con la dirección, bajo esta premisa, la 
sostenibilidad de las mipyme depende mucho de la gestión administrativa de sus recursos internos. Molina et al., (2019) plantean que: "En ese sentido los aspectos internos tienen mayor relevancia para la supervivencia de las micro y pequeñas empresas debido a su tamaño la participación del empresario y colabores es ineludible (pág. 294).

Para el logro de las metas de la organización es necesario una visión conjunta por parte de la gerencia y los colaboradores que permita interiorizar la importancia del conocimiento y ejecución de una buena gestión administrativa de sus recursos, en la cual se unifique intereses que conlleve a consolidar esfuerzos en una misma dirección.

\section{Gestión financiera contable}

La importancia de la gestión financiera en la mipymes radica en el control de todas las operaciones, que permitan una eficaz toma de decisiones y en mantener la efectividad y eficiencia operacional. Se debe caracterizar por generar información útil para la gestión de la empresa, sencillo y ágil, fácil de utilizar para efectos fiscales, la confiabilidad de la información financiera y el cumplimiento de las regulaciones existentes de acuerdo a las normas internacionales de contabilidad (NIIF), (Bertolino et al., citados por Saavedra, Tapia y Aguilar (2016)).

La administración de los recursos financieros es uno de los puntos críticos en la gestión empresarial, la disponibilidad de los recursos monetarios, la eficiente gestión oportuna de estos y la asignación adecuada, son determinantes en la capacidad de respuesta que se tenga ante las distintas actividades derivadas de las estrategias definidas. La disponibilidad y manejo eficiente de los recursos financieros permite a la organización mayor maniobrabilidad ante situaciones inesperadas $\mathrm{u}$ oportunidades que se presenten generando mayor competitividad en un entorno cambiante como el actual.

Las mipymes deben enfocarse en llevar un estricto control interno de sus recursos, por lo general los mayores problemas que presentan son la falta de control de inventarios, registro de ingresos y egresos, presupuesto de compras, disponibilidad de efectivo, falta de capacidad de pago de factura de proveedores.

El manejo de los recursos financieros requiere de la aplicación de normas y procedimientos para lograr los resultados esperados. Rodríguez (2016) refiere que muchas de las dificultades económicas que presentan las empresas se originan por algún desequilibrio financiero imprevisto, caracterizado por insolvencia y poca liquidez, como producto de políticas financieras poco efectivas ocasionadas por el poco conocimiento administrativo de los propietarios o gerentes en el manejo eficaz de los recursos. 
Algunas empresas por considerarse pequeñas no realizan control contable de sus recursos, esto puede ser por la falta de conocimiento o porque no le dan importancia a este proceso; las consecuencias son en algunos casos catastróficas ya que no se dan cuenta si están teniendo pérdidas, teniendo como efecto inmediato la insolvencia para hacerle frente a sus obligaciones llegando en el peor de los casos a perder activos fijos del patrimonio familiar para hacerle frente a las deudas contraídas.

Un buen análisis financiero facilita la toma de decisiones ya que genera información sobre los aspectos económicos y financieros que muestran las condiciones en que opera la empresa. Guerrero y Galindo (2014) indican que un buen control financiero contable permite conocer el comportamiento del capital en relación con las utilidades o pérdidas obtenidas durante el ejercicio, la adecuada inversión en bienes propios para la realización de las operaciones de la organización, enterarse del monto de los ingresos y egresos generados durante un periodo determinado, conocer a cuánto ascienden las deudas y sus plazos producto de las actividades realizadas en la empresa.

La salud financiera de una empresa está determinada por un buen sistema de información contable actualizado, que brinde una radiografía que permita tomar las decisiones oportunas o visibilizar las áreas donde se estén presentando problemas, lo cual ayudará a tomar las medidas correctivas que permitan el uso eficiente de los recursos.

\section{Gestión del talento humano}

En la micro, pequeña y mediana empresa, la gestión del talento humano debe verse como un proceso formal ya que muchas veces por contar con poco personal no le dan importancia y no definen claramente las características que estos requieren. Deben considerar que este proceso tiene que ser diseñado para atraer, gestionar, desarrollar, motivar y retener a los colaboradores.

La gestión del talento humano debe estar orientada a obtener mejores resultados con la colaboración de cada uno de los empleados ya que el accionar de las personas afecta positiva o negativamente, estos resultados están condicionados por la implementación de un buen proceso de selección, evaluación, capacitación y monitoreo, (Chiavenato, 1999) (como se citó en Galarza et al. (2020)). Cuando se lleva a cabo una correcta administración de los recursos humanos el desempeño de los colaboradores es más productivo.

Una adecuada gestión de los recursos humanos es determinante para la ejecución de las tareas de manera eficiente y eficaz, mediante esta se selecciona a las personas idóneas a un puesto, pero para esto es necesario que la empresa lleve a cabo un buen proceso de reclutamiento, selección, inducción y capacitación del nuevo colaborador, de igual manera evaluar el desempeño y garantizar el bienestar y satisfacción del trabajador mediante una remuneración y un clima organizacional satisfactorio. 
Adicionalmente a la correcta selección y capacitación de sus recursos humanos, se debe comprender que la capacidad competitiva de toda empresa está determinada principalmente por el buen desempeño de sus recursos humanos y que para lograr esto debe existir satisfacción de la persona en su trabajo; esto implica que la organización no solo debe velar porque el colaborador posea las habilidades y destrezas requeridas, sino también que sus objetivos y aspiraciones individuales sean congruentes con los objetivos de la organización.

Una carencia en la gestión del talento humano limita la generación de competencias del personal, esto se da muchas veces porque el área de Recursos Humanos no es manejada por una persona dedicada exclusivamente a esta actividad que posea los conocimientos necesarios de los distintos componentes de la administración de personal y que sea capaz de diseñar políticas, programas y estrategias requeridas en esta área (Mora Gómez, 2008).

Al existir un débil manejo de los recursos humanos trae como consecuencia que no se dé un desarrollo organizacional adecuado y que muchas veces el personal no tenga las competencias necesarias, producto de la inexistencia o deficiente planificación de las capacidades y habilidades requeridas, las cuales están condicionadas a los cambios sociales, de mercado, la internacionalización y el aumento de la competitividad.

Una efectiva administración de los recursos humanos en la mipyme identifica las necesidades de capacitación, retroalimentación y el apoyo, que requieren los colaboradores, así como tener una visión clara de las competencias que necesitan para alcanzar el éxito personal y organizacional.

\section{Gestión de abastecimiento}

Hoy más que nunca el mercado es más exigente, por lo que para competir con empresas nacionales e internacionales las mipymes necesitan atender de la mejor manera a todos y a cada uno de sus clientes, de ahí la necesidad de una gestión integrada de la cadena de suministro y las redes de valor, que permitan efectivas relaciones interempresariales que incidan en su competitividad, por lo que la integración de cada uno de los eslabones de la cadena de suministro debe ser un objetivo primario para alcanzar una sólida posición competitiva (Quiala et al., (2018)). Al existir una logística integrada con sus proveedores va a permitir satisfacer en tiempo y forma las necesidades de sus clientes.

El proceso de gestión de abastecimiento conlleva alinear los distintos procesos logísticos y sus actores que permitan satisfacer las necesidades de los clientes generando valor agregado optimizando sus recursos (Gómez, Zuluaga, Ceballos (2019)), como resultado, una buena gestión se ve reflejada en el 
incremento de las utilidades de la empresa, la productividad y la satisfacción del cliente en la demanda de productos.

Un aspecto esencial para tener un buen posicionamiento, radica en el abastecimiento de productos al mercado en el momento que lo requieren, una empresa que no logra este cometido con sus clientes o consumidores, no solamente pierde las utilidades generadas por la venta, sino la confianza y fidelidad de los mismos al generar incertidumbre de la existencia del surtido requerido en el negocio.

\section{Gestión del conocimiento e innovación}

La Gestión del conocimiento y la innovación se caracteriza por el uso de tecnologías electrónicas de comunicación, la globalización y cambios en los procesos productivos como resultado de la investigación. Implica que las organizaciones deben analizar de manera constante el ambiente empresarial que le rodea diseñando sistemas de información que permitan a la empresa solucionar problemas y elaborar estrategias competitivas para posicionarse de manera efectiva en el mercado.

La gestión del conocimiento adquiere importancia en la medida que apoya la estrategia empresarial. Es un proceso que sirve de apoyo a las organizaciones para generar información relevante que contribuya a la solución de problemas y la toma de decisiones (Torres y Lamenta, citados por Solís (2018)). Esto requiere tomar en cuenta a todo el personal activo en el flujo de información relevante que requieren en sus actividades.

En cuanto a la gestión de la innovación, Alliance (como se citó en Igartua (2009)), la define como:

La gestión del proceso de innovación al objeto de asegurar la existencia de una estrategia, planes y cultura empresarial que promuevan la innovación. Más concretamente la gestión de la innovación hace referencia al desarrollo y lanzamiento de nuevos productos, servicios tecnologías, conceptos o procesos al mercado de tal forma y manera que se maximice la generación de ideas y potencial innovador de la empresa, ya que es un paragua estratégico, a diferencia de la gestión de productos, que se centra en aspectos más tácticos y operativos. (pág. 51)

En las circunstancias actuales la gestión del conocimiento e innovación es vital para las mipymes, se traduce en la transferencia de conocimiento y la experiencia existente entre los miembros de una organización, de tal forma que pueda ser utilizado posteriormente como un recurso disponible. Este propósito, se puede alcanzar de manera formal por medio del aprendizaje, el entrenamiento profesional y los programas de capacitación, que permita a los colaboradores estar actualizados en cuanto al conocimiento de nuevas técnicas, métodos, tecnología y las tendencias en cuanto al comportamiento del mercado. 


\section{Gestión de comercialización}

Toda empresa que ofrece un producto o servicio requiere de recursos y técnicas diseñadas para dar a conocer una propuesta comercial, un producto o un servicio. La gestión comercial podría considerarse como el canal de comunicación que tiene una empresa con los consumidores. Una de las mayores dificultades de las mipymes es diseñar las estrategias para que conozcan su producto o servicio y la forma de cómo llegar a su mercado meta, siguen recurriendo a métodos obsoletos y desaprovechando el beneficio que brinda las TIC a través del uso del internet mediante redes sociales y páginas web, que permiten llegar de manera precisa a los segmentos idóneos.

Fundamentando los aspectos para una correcta gestión de mercadeo, Cantillo (2013) afirma que: "Aunque en esencia sea muy parecida en todos los escenarios globales, debe tener en cuenta factores que son propios de cada región, o de cada grupo de consumidor, para así adaptarse a esa situación y establecer la gestión de mercadeo adecuada" (pág. 143).

Lograr una buena gestión comercial conlleva una serie de actividades, tales como un estudio exhaustivo del mercado, la planificación de objetivos concretos, los medios de distribución, entre otros aspectos. Es un proceso que define los pasos a seguir para alcanzar la meta de ventas, buscando sobre todo la satisfacción del cliente.

En este proceso se tiene que partir de la segmentación de mercado y la definición de su mercado meta evaluando los segmentos más factibles y rentables:

No existe una forma única para segmentar un mercado. El mercadólogo tiene que probar variables diferentes de segmentación, solas y combinadas, hasta encontrar la mejor forma de ver la estructura del mercado. Entre las principales variables están las geográficas, demográficas, psicográfica, y conductuales. (Kotler \& Armstrong, 2008, pág. 165)

Definir de manera clara el o los segmentos de mercado hacia el cual la empresa orientará sus esfuerzos de mercadotecnia, es esencial para dirigir los recursos hacia las personas que serán su mercado meta. Al identificar los posibles consumidores permitirá establecer el plan de mercadeo de manera correcta para así establecer su posicionamiento en el mercado.

Una vez determinado en qué segmentos del mercado entrará, la empresa deberá decidir que posiciones quiere ocupar en esos segmentos: "El enfoque fundamental del posicionamiento no es crear algo nuevo y diferente, sino manipular lo que ya está en la mente; reordenar las conexiones que ya existen" (Ries \& Trout, 1990, pág. 1).

Definido el mercado meta y la forma de posicionamiento, se debe formular las estrategias competitivas que permitan diferenciarse de la competencia; la 
estrategia es la forma en que los objetivos se operacionalizan en la cual se establece la secuencia de las acciones a realizar para el logro de las metas organizacionales (Mintzberg, Quinn, \& Voyer, 1997). Los objetivos establecen lo que la organización pretende alcanzar, las estrategias definen la manera de lograrlos.

Al seleccionar una estrategia es fundamental establecer lo que es de valor para el cliente en el producto o servicio que se le ofrece, al respecto valor para el cliente es la evaluación que realiza el cliente en cuanto a las diferencias que percibe de los beneficios que ofrece la empresa con respecto a la oferta de los competidores (Kotler \& Arsmtrong, 2007). Esta percepción del consumidor es determinante en la fidelidad que tenga hacia la empresa y en la posición competitiva de la misma.

Dentro del desarrollo de las estrategias de la mezcla de mercadotecnia por parte de las mipymes se le debe dar singular importancia el merchandising, el cual consiste en:

Conjunto de estudios y técnicas de aplicación llevados a la práctica, de forma conjunta o separada, por distribuidores y fabricantes con el objeto de aumentar la rentabilidad del punto de venta y dar mayor salida a los productos, mediante una permanente adaptación del surtido a las necesidades del mercado y la presentación apropiada de las mercancías. (GALICIA, 2010, pág. 11)

El merchandising es una herramienta competitiva de gran importancia para las mipymes, se enfoca en la imagen y presentación para hacer más llamativo y atractivo el negocio en el punto de venta, por lo que comprende elementos tanto externos como internos del negocio. En el exterior se debe cuidar la fachada, el rótulo, accesibilidad y entrada y el escaparate. En el interior se debe dar singular importancia a la distribución de la superficie de ventas, el mobiliario, la presentación y distribución del producto, la ambientación (luz, color, música, temperatura, aromas).

\section{La gestión empresarial como sistema}

Toda organización es un sistema, el cual está formado por distintas áreas o departamentos que la componen, que, aunque tengan funciones diferentes tienen como fin los mismos objetivos organizacionales. Uno de los mayores problemas presentes en algunas organizaciones es el aislamiento de las unidades o áreas que persiguen objetivos de manera individual muchas veces afectando a las otras. Esto genera que las organizaciones no logren ser eficientes ni eficaces con sus recursos y en algunas ocasiones pierdan oportunidades que se presentan en el entorno. Un recurso valioso que los miembros de las distintas áreas deben compartir es la información, esta es como la sangre que alimenta y oxigena haciendo a la organización más dinámica y competitiva. 
De manera general, son pocas las organizaciones que cuentan con un plan de información que contemple el desarrollo de un sistema informativo integrado, que, normalmente suele estar fragmentado por departamentos o áreas de la organización y no suele haber un responsable de la integración y organización global del sistema informativo.

Debido a esta problemática que ha sido una constante en algunas empresas que afecta su competitividad y sostenibilidad, existe mayor preocupación por integrar los sistemas de gestión de las distintas unidades o áreas, esto comprende una mejor planificación y control de los procesos de la organización para ofrecer productos que cumplan con las exigencias de los clientes y por otro lado preservar el ambiente y garantizar la salud y seguridad de los trabajadores (Cabrera, Medina, Abab, Nogueira y Núñez, (2015)). El desempeño de la organización como un sistema con sus componentes unificados hacia un mismo propósito, permite la definición clara de estrategias de diferenciación que estén orientadas al logro de los objetivos, estando dentro de estos tener una posición clara en el mercado y lograr una buena competitividad mediante la eficiente gestión de sus recursos.

\section{CONCLUSIONES}

En este artículo se abordan los diferentes postulados teóricos que han aportado a la Administración, desde los diferentes precursores, lo cual sirve de base para la gestión empresarial en las distintas áreas de una organización. De igual manera, se desarrolló los aspectos fundamentales de los distintos tipos de gestión empresarial para la efectiva optimización de los recursos que posicione a una mipyme de manera competitiva.

La gestión empresarial comprende el manejo y optimización de los recursos que posee la empresa a fin de alcanzar los objetivos organizacionales, para lograrlo se requiere de una serie de acciones y el involucramiento de las distintas áreas de una organización que actúen de manera articulada sustentados por un sistema efectivo de comunicación lo cual permitirá mejorar su posicionamiento y competitividad.

Desde la Administración Científica se identifican los aportes de Taylor y Fayol orientados a mejorar la productividad desde el enfoque del trabajador y desde la perspectiva de la dirección.

De manera consecutiva, se abordan distintas teorías que vinieron a complementar la ciencia administrativa, siendo de singular importancia: las relaciones humanas, del comportamiento y del desarrollo organizacional que rechazaron la visión del hombre como máquina y se orientaron hacia la motivación del trabajador. Posteriormente, se identifica los aportes de 
las teorías de sistemas, burocrática y de contingencia que definieron los conceptos de organización como sistemas, el establecimiento de normas y procedimientos y el enfoque situacional respectivamente.

Los fundamentos teóricos desarrollados en estos planteamientos, son la base para el desempeño de manera ordenada, estructurada y congruente de las actividades de las empresas en la actualidad, que con los adelantos tecnológicos han simplificado las tareas mediante la elaboración de modelos matemáticos que facilitan la toma de decisiones, pero sin apartarse de los principios administrativos desarrollados por los autores estudiados en ese artículo.

Cada uno de los distintos subsistemas de la gestión de una empresa se enfoca en las actividades tanto internas para el control y optimización de los recursos, como a nivel externo para elaborar estrategias que permitan aprovechar las oportunidades y contrarrestar las acciones de la competencia. El propósito de estos subsistemas debe estar encaminado hacia la unificación de esfuerzos que permita el logro de los objetivos organizacionales.

Al estar las empresas formadas por diferentes subsistemas, estos, en muchas organizaciones no actúan de manera coordinada, afectando la velocidad en la toma de decisiones y en el aprovechamiento de las oportunidades de mercado, por tal razón, se requiere adoptar un enfoque de sistema en el cual, de manera integrada fluya la información en todos los niveles de la estructura organizativa.

Estos subsistemas se orientan a gestionar los recursos administrativos, humanos, financiero contable, de abastecimiento, de comercialización y del conocimiento e innovación, los cuales se consideran como los básicos para la sostenibilidad de una mipyme. 


\section{REFERENCIAS}

Amorós, E.,Becerra,J.,\&Díaz, D. (2007). GestiónEmpresarialpara agronegocios. Chiclayo, Perú: eumed.net. Recuperado el 25 de Septiembre de 2020, de https://elibro.net/es/ereader/unanmanagua/51608? page $=1$

Araujo Lobo, A. (Enero de 2015). Cameralismo: un antecedente más en la evolución de la administración como ciencia. (V. Gerencial, Ed.) redalyc. org(1), 165-180. Recuperado el 07 de Septiembre de 2020, de https:// www.redalyc.org/articulo.oa? id $=465545898008$.

Cabrera, H. R., Medina León, A., Abab Puente, J., Nogueira Rivera, D., \& Nuñez Chiaviano, Q. (2015). La integración de Sistemas de Gestión Empresariales, conceptos, enfoques y tendencias. (I. d. Tecnología, Ed.) Ciencias de la Información, 46(3), 3-8. Recuperado el 10 de Octubre de 2020, de https://www.redalyc.org/pdf/1814/181443340001.pdf

Cantillo Guerrero, E. (2013). Factores claves en la gestión de mercadeo, que inciden en la competitividad del sector de comunicaciones gráficas de la ciudad de Barranquilla, Colombia. Rev. esc.adm.neg. No. 75(75), 140-151. Recuperado el 26 de Septiembre de 2020, de http://search. ebscohost.com/login. aspx? direct=true \&db=asn\&AN=95028137\&lang $=$ es\&site $=$ ehost-live

Chiavenato, I. (2007). Introducción a la teoría general de la administración. Séptima edición. México, México: Mcgraw-hill/interamerícana EDITORES, S.A. DE C.V.

Galarza Villalba, M. F., Mora Romero, J. L., \& Zambrano Campi, D. (2020). Gestión administrativa, la sostenibilidad de las agrupaciones rurales en la provincia de los Rio-Ecuador. Revista Dilemas Contemporáneos: Educación, Política y Valores., 21. Recuperado el 26 de Septiembre de 2020, de http://search.ebscohost.com/login.aspx?direct=true\&db=fap\& AN $=141887637$ \&lang $=$ es\&site $=$ ehost-live

GALICIA, S. (2010). Como aplicar el Merchandising en mi establecimiento. (C. G. S.A., Ed.) Recuperado el 12 de Octubre de 2020, de https://issuu.com: https://issuu.com/josevalencia/docs/como_aplicar_el_merchandising_ en mi

Gómez Montoya, R. A., Zuluaga Mazo, A., Ceballos Atehourtua, N., \& Palacio Jiménez, D. (2019). Gestión de la cadena de suministros y productividad en la literatura científica. I+D Revista de Investigaciones, 34. Recuperado el 12 de Octubre de 2020, de https://www.researchgate. net/publication/333540042_Gestion_de_la_cadena_de_suministros_y_ productividad_en_la_literatura_cientifica

Guerrero Reyes, J. C., \& Galindo Alvarado, J. F. (2014). Contabilidad para administradores. México: Grupo editorial Patria. Recuperado el 26 de Septiembre de 2020, de https://elibro.net/es/ereader/ unanmanagua $/ 39381$ ? page $=17$

Guízar Montúfar, R. (2013). Desarrollo organizacional principios y aplicaciones (Vol. Cuarta edición). México: Mc Graw Hill Education. Recuperado el 12 
de Octubre de 2020, de https://www.academia.edu/33195212/Libro_ Desarrollo_Organizacional

Hernández Palma, H. G. (2011). La gestión empresarial, un enfoque del siglo $X X$, desde las teorías administrativas científica, funcional, burocrática y de relaciónes humanas. Dialnet, 9(1), 38-51. Recuperado el 08 de Septiembre de 2020, de https://dialnet.unirioja.es/servlet/articulo? codigo $=3875234$ Igartua López, J. I. (2009). Gestión de la Innovación en la empresa Vasca. (U. P. Valencia, Ed.) Recuperado el 14 de Septiembre de 2020, de https:// riunet.upv.es/: $\quad$ https://riunet.upv.es/bitstream/handle/10251/7202/ tesisUPV3154.pdf

Inciarte, A., Marcano, N., \& Reyes, M. E. (2006). Gestión académicoadministrativa en la educación básica. Revista Venezolana de Gerencia, 11(34), 230-231. Obtenido de https://www.redalyc.org/ pdf/290/29003405.pdf

Koontz, H., Weihrich, H., \& Cannice, M. (2012). Administración: Una perspectiva global y empresarial Decimocuarta edición. Méxcio: McGraw Hill Educacion.

Kotler , P., \& Arsmtrong, G. (2007). Marketing Versión para Latinoamérica (Decimoprimer edición ed.). México: PEARSON Educación.

Kotler, P., \& Armstrong, G. (2008). Fundamentos de Marketing (Octava ed.). (G. R. Miguel, Ed.) México: Pearson Educación de Mexico, S. A. de C. V.

López, P. A., \& Mariño Arevalo, A. (2010). Hacia una evolución en el campo del conocimiento de la disciplina administrativa: De la Administración de empresas a la Gestión de organizaciones. Revista de la Facultad de Ciencias Económicas: Investigación y Reflexión, XVIII(2), 75-95. Recuperado el 11 de Septiembre de 2020, de https://www.redalyc.org/ articulo.oa? id $=90920053004 \&$ idp $=1$ \&cid $=938189$

Mintzberg, H., Quinn, J. B., \& Voyer, J. (1997). El Proceso Estratégico. México: Prentice Hall Hispanoamericana,S. A. .

Molina Corral, L. A., Piñón Howlet, L. C., Sapién Aguilar, A. L., \& Gallegos Cereceres, V. M. (2019). Análisis de las Habilidades Administrativas y de Gestión en las Micro y Pequeñas Empresas de la ciudad de Chihuahua. Nova Scientia, 11(22), 293-322. Recuperado el 25 de Septiembre de 2020, de http://search.ebscohost.com/login.aspx? direct=true\&db=asn\& $\mathrm{AN}=137197180$ \&lang $=$ es\&site $=$ ehost-live

Mora Gómez, N. A. (2008). ¿̇Es la gestión del talento humano un factor de competitividad en las pymes en la ciudad de pasto? (U. Mariana, Ed.) Revista UNIMAR, 26(2). Recuperado el 12 de Septiembre de 2020, de http://editorial.umariana.edu.co/revistas/index.php/unimar/article/ view/86

Quiala-Tamayo, L., Fernández Nápoles, Y., Vallín-García, A. E., Lopes Martínez, I., Domínguez-Pérez, F., \& Calderio Rey, Y. (2018). Una nueva visión en la gestión de la logística de aprovisionamientos en la industria biotecnológica cubana. VacciMonitor. Recuperado el 12 de Octubre de 2020, de https://www.medigraphic.com/pdfs/vaccimonitor/vcm-2018/ vcm 183c.pdf

Ramirez Cardona, C. (2010). Fundamentos de Administración tercera edición. 
Bogotá, Colombia: ECOE Ediciones. Recuperado el 08 de Septiembre de 2020

Reyes Ponce, A. (2007). Administración Moderna. México: LIMUSA S.A. de C.V.

Ries, A., \& Trout, J. (1990). Posicionamiento. México: Mc-Graw-Hill / Interamericana de España, S. A.

Rivas Márquez, G. (Julio de 2011). Modelos contemporáneos de control interno. Fundamentos teóricos. Observatorio Laboral Revista Venezolana, 4(8), 115-136. Recuperado el Septiembre de 2020, de https://www. redalyc.org/articulo.oa? id $=219022148007$

Rodríguez Salazar, P. D. (2016). Gestión Financiera en PyMES. (C. E. SER, Ed.) Revista Publicando, 3(8), 588-596. Recuperado el 13 de Septiembre de 2020, de https://revistapublicando.org/revista/index.php/crv/article/ view/331

Saavedra Garcia, M. L., Tapia Sanchez, B., \& Aguilar Anaya, M. d. (Septiembre de 2016). La gestión financieraen las pymes del Distrito Federal, Mexico. (researchgate.net/publication, Ed.) Revista Perspectiva Empresarial, 3(2), 55-69. doi:10.16967/rpe.v3n2a5

Sánchez Ambriz, G. (2009). El desarrollo organizacional: una estrategia de cambio para las instituciones documentales. Anales de Documentación, 235-254. Recuperado el 24 de Marzo de 2021, de https://www.redalyc. org/pdf/635/63511932013.pdf

Solís Cedeño, V. J. (2018). "La gestión administrativa y su incidencia en la sostenibilidad financiera de las pymes formales del sector manufacturero de la provincia de Manabí -República de Ecuador". Obtenido de http://cybertesis.unmsm.edu.pe/bitstream: http://cybertesis. unmsm.edu.pe/bitstream/handle/20.500.12672/10049/Solis_ cv.pdf? sequence $=1$ \&isAllowed $=y$

Zapata Rotundo, G. (2014). El determinismo en la teoría contingente: orígenes de sus fundamentos. (I. T. Domingo, Ed.) Ciencia y Sociedad, 39(1), 121-154. Recuperado el 08 de Septiembre de 2020, de https:// www.redalyc.org/pdf/870/87031229006.pdf 